\title{
Micromechanical Fast Quasi-Static Detection of and Relaxations with Nanograms of Polymer
}

Bose, Sanjukta; Schmid, Silvan; Larsen, Tom; Keller, Stephan Sylvest; Boisen, Anja; Almdal, Kristoffer

Published in:

Journal of Polymer Science. Part B, Polymer Physics

Link to article, DOI:

10.1002/polb.23745

Publication date:

2015

Document Version

Peer reviewed version

Link back to DTU Orbit

Citation (APA):

Bose, S., Schmid, S., Larsen, T., Keller, S. S., Boisen, A., \& Almdal, K. (2015). Micromechanical Fast QuasiStatic Detection of and Relaxations with Nanograms of Polymer. Journal of Polymer Science. Part B, Polymer Physics, 53(15), 1035-1039. https://doi.org/10.1002/polb.23745

\section{General rights}

Copyright and moral rights for the publications made accessible in the public portal are retained by the authors and/or other copyright owners and it is a condition of accessing publications that users recognise and abide by the legal requirements associated with these rights.

- Users may download and print one copy of any publication from the public portal for the purpose of private study or research.

- You may not further distribute the material or use it for any profit-making activity or commercial gain

- You may freely distribute the URL identifying the publication in the public portal 


\title{
Micromechanical fast quasi-static detection of $\alpha$ and $\beta$ relaxations with nanograms of polymer
}

\author{
Sanjukta Bose ${ }^{1}$, Silvan Schmid ${ }^{1}$, Tom Larsen ${ }^{2}$, Stephan Sylvest Keller ${ }^{1}$, Anja Boisen $^{1}$, Kristoffer Almdal $^{1}$ \\ ${ }^{1}$ Department of Micro- and Nanotechnology, Technical University of Denmark, DTU Nanotech, DK-2800 \\ Kongens Lyngby, Denmark \\ ${ }^{2}$ Department of Mechanical Engineering, Stanford University, Stanford, CA 94305, USA \\ Correspondence to: Sanjukta Bose (E-mail: sbos@nanotech.dtu.dk)
}

\begin{abstract}
Micromechanical string resonators are used as a highly sensitive tool for the detection of glass transition ( $T_{g}$ or $\alpha$ relaxation) and sub- $T_{g}$ ( $\beta$ relaxation) temperatures of polystyrene (PS) and poly (methyl methacrylate) (PMMA). The characterization technique allows for a fast detection of mechanical relaxations of polymers with only few nanograms of sample in a quasi-static condition. The polymers are spray coated on one side of silicon nitride (SiN) microstrings. These are pre-stressed suspended structures clamped on both ends to a silicon frame. The resonance frequency of the microstrings is then monitored as a function of increasing temperature. $\alpha$ and $\beta$ relaxations in the polymer affect the net static tensile stress of the microstring and result in measureable local frequency slope maxima. $\mathrm{T}_{\mathrm{g}}$ of PS and PMMA is detected at $91 \pm 2^{\circ} \mathrm{C}$ and $114 \pm 2^{\circ} \mathrm{C}$ respectively. The results match well with the glass transition values of $93.6^{\circ} \mathrm{C}$ and $114.5^{\circ} \mathrm{C}$ obtained from Differential Scanning Calorimetry (DSC) of PS and PMMA respectively. The $\beta$ relaxation temperatures are detected at $30 \pm 2^{\circ} \mathrm{C}$ and $33 \pm 2^{\circ} \mathrm{C}$ for PS and PMMA which is in accordance with values reported in literature.
\end{abstract}

Over the years, relaxation processes in amorphous polymers have been widely studied. The glass transition temperature $\left(T_{g}\right)$, also known as the $\alpha$ relaxation, is the characteristic temperature for a polymer where the longrange segmental motion starts. The $\alpha$ relaxation temperature of a polymer is an important parameter for processing and end-use applications. Below the $\alpha$ relaxation temperature, a considerable amount of local motions in the form of simple bond rotation or conformational changes inside molecular groups are present, corresponding to secondary relaxation processes like $\beta$ relaxations. ${ }^{1}$ These secondary chain motions respond to the applied stress and thus the process of $\beta$ relaxations can impart the toughness to some polymers. ${ }^{2}$ Common techniques used to determine the relaxation temperatures of polymers are differential scanning calorimetry (DSC), thermomechanical analysis (TMA), dynamic mechanical analysis (DMA), and dielectric spectroscopy (DES). Among these, DSC is the most common method for detecting $\alpha$ relaxation temperature of polymers. But DSC can be unsuitable for relaxations with low calorimetric effects like in some pharmaceutical products $^{3}$, proteins ${ }^{4}$, or $\beta$ relaxations where the associated change in heat capacity is too small. In such cases it is more applicable to measure mechanical or electrical properties of the sample with TMA, DMA, or DES. ${ }^{5}$ TMA can be used to detect $\alpha$ relaxations of polymers but it is not recommended for detecting weak $\beta$ relaxations. ${ }^{6,7}$ Both DMA and DES can be successfully used to detect $\alpha$ and $\beta$ relaxation in polymers. DES is preferred in most cases due to its high sensitivity and wide dynamic range. ${ }^{7-9}$ 
Nevertheless all these above mentioned state of the art techniques have their own advantages and disadvantages. In case of DSC for example, a higher heating rate increases the instrument sensitivity but at the cost of broadening of the shape of the relaxation curves and shifting of $\mathrm{T}_{\mathrm{g}}$ to higher temperatures. In TMA on the other hand, the accuracy of the results is sensitive to probe loading conditions. Moreover for precise measurements by TMA, a low heating rate $\left(1-5^{\circ} \mathrm{C} / \mathrm{min}\right)$ should be maintained and a minimum sample thickness of $\sim 0.5 \mathrm{~mm}$ is required. ${ }^{10}$ Glass transition is a kinetically controlled second order transition that depends on the applied oscillation frequency (in case of DMA) and frequency of the applied alternating current (in case of DES). In particular for DES, the sample should also possess moderate to strong polarizability. ${ }^{10}$ For comparison with transition values obtained from other thermal methods, DMA and DES are often run at low frequency $(\sim 1 \mathrm{~Hz})$ and low heating rates $\left(\sim 2^{\circ} \mathrm{C} / \mathrm{min}\right)$ which in turn adds on to the total experimental time. ${ }^{6,7,10}$

Micromechanical string resonators are powerful tools for polymer characterization which i) are sensitive in measuring $\alpha$ and $\beta$ relaxations, ii) can measure in quasi-static conditions and thus eliminate the frequency dependency of $T_{g}$, iii) allow fast heating rates which reduces experimental time, and iv) can analyse nanogram samples. Micro sized beam resonators have been developed as highly sensitive sensors for sensing chemicals, humidity, mass or temperature. ${ }^{11-15}$ In our previous work ${ }^{16}$ it was shown that silicon nitride (SiN) microstrings can be used as a new analytical tool now named as microstring thermal analyzer (MTA) for detecting the $\alpha$ relaxation of polymers with only few nanograms of sample. This is six orders of magnitude less sample than required for DSC. Furthermore, there is no need for bulk samples, as they have to be prepared for TMA, DMA or DES. The small sample mass on the microstrings attains fast thermal equilibrium and thus higher heating rates can be used without affecting the transition temperatures, thereby reducing the experimental timeframe. Microstrings are doubly-clamped pre-stressed SiN beams on a silicon ( $\mathrm{Si}$ ) frame. Minute changes of the tensile stress in the microstring can be detected with high sensitivity due to the mechanical resonance frequency detuning. When these strings are coated with polymers and subjected to heating cycles, the heating-related expansion and softening of the polymer causes a net change in the static tensile stress. The mechanical relaxations of the polymer under test can be detected from the slope maxima of the resonance frequency versus temperature. A comparison between the conventional techniques discussed above and our new tool MTA is presented in Table 1.

Table 1. Summary of different techniques used to determine $\alpha$ and $\beta$ relaxations of polymers $^{6,7,10,16,17}$

\begin{tabular}{cccccc}
\hline Tool & $\boldsymbol{\alpha}$ & $\boldsymbol{\beta}$ & $\begin{array}{c}\text { Frequency } \\
\text { dependency }\end{array}$ & $\begin{array}{c}\text { Heating } \\
\text { rate } \\
\left({ }^{\circ} \mathrm{C} / \mathrm{min}\right)\end{array}$ & $\begin{array}{c}\text { Sample } \\
\text { size }\end{array}$ \\
\hline DSC & $\checkmark$ & $\mathbf{x}$ & $\mathbf{x}$ & $5-10$ & $3-10 \mathrm{mg}$ \\
TMA & $\checkmark$ & $\boldsymbol{x}$ & $\boldsymbol{x}$ & $1-5$ & Bulk \\
DMA & $\checkmark$ & $\checkmark$ & $\checkmark$ & $\leq 2$ & Bulk \\
DES & $\checkmark$ & $\checkmark$ & $\checkmark$ & $\leq 2$ & Bulk \\
MTA & $\checkmark$ & $\checkmark$ & $\times$ & $15-30$ & $5-10 \mathrm{ng}$ \\
\hline
\end{tabular}

In this work, the potential of MTA to quasistatically detect the more subtle $\beta$-relaxation of nanograms of polymer is evaluated. For this purpose polystyrene (PS) and poly (methyl methacrylate) (PMMA) are spray coated onto the microstrings. Temperature induced changes in the resonance frequency of the strings are monitored and compared with DSC results and literature reference values.

First we analyzed PS with the MTA technique. Figure 1a shows the change in resonance frequency of a blank $\left(f_{\text {blank }}\right)$ and PS coated $\left(f_{\text {coated }}\right)$ microstring. The derivative plot of $f_{\text {coated, }}$ with respect to the temperature $(T)$, is shown in 
Figure $1 \mathrm{~b}$. The corresponding DSC thermogram of PS is shown in Figure 2.

The vibrational frequency is a direct measure for the tensile stress in the strings. It is a common valid assumption that the small modulation of the tensile stress by the vibration of the microstring is negligible ${ }^{18}$ since the strings have a very high static pre-stress of $\sim 190 \mathrm{MPa}$. Hence, the measured change in tensile stress represents the quasi-static thermal response of the polymer, which is independent of the vibrational frequency of the string. The actual value of the resonance is irrelevant and not comparable to the applied frequencies in either DMA or DES. When the temperature is ramped up, the microstrings show an increase in resonance frequency due to a heat induced static stress change. From Figure $1 \mathrm{a}$, it is observed that the resonance frequency of the blank microstring (dotted line) increases linearly with temperature. The Si frame has a higher thermal expansion, $2.6 \mathrm{ppm} / \mathrm{K}$, compared to SiN microstrings, $1.25 \mathrm{ppm} / \mathrm{K}$, and thus the frame expands more than the microstrings. As a result, the tensile stress in the microstrings increases which is reflected by an increase in resonance frequency. The PS coated microstring in contrast (Figure 1a, solid line) shows a lower absolute resonance frequency than the reference microstrings due to the added mass. When the PS coated string is heated, the resonance frequency increases with a varying slope over the measured temperature range. At higher temperatures, the resonance frequency starts to increase linearly, similar like the bare reference microstrings. This is expected due to the drastic drop of Young's Modulus of PS above $\mathrm{T}_{\mathrm{g}}{ }^{2}$

The mechanical relaxations of the polymer film correspond to the temperatures of maximal frequency change. From Figure $1 b$, it can be seen that there is a small broad peak at $30.1^{\circ} \mathrm{C}$ followed by a sharp peak at $91.3^{\circ} \mathrm{C}$. The maximum peak at $91.3^{\circ} \mathrm{C}$ matches well with the DSC results of $93.6^{\circ} \mathrm{C}$, as shown in Figure 2 , and thus it is confirmed as the $\alpha$ relaxation peak of PS.

From several sources in literature, ${ }^{1,19-22}$ it has been observed that the $\beta$ relaxation of PS appears in between $27-37^{\circ} \mathrm{C}$, measured both by DES and DMA. Thus, the small broad peak at $30.1^{\circ} \mathrm{C}$ seems to represent the $\beta$ relaxation peak of PS. It is known from both DES and DMA that the $\beta$-relaxation is best observed at low frequency $^{21}$ and often the $\beta$ peaks are not resolved when the applied frequency is high. ${ }^{20,23}$ Since the MTA method operates in the quasistatic regime, it allows for the detection of a pronounced $\beta$-relaxation peak. The rotational motion of the phenyl rings on the PS backbone (Figure $1 b$, inset) may contribute to the $\beta$ relaxation process ${ }^{24}$, but this remains an open discussion.

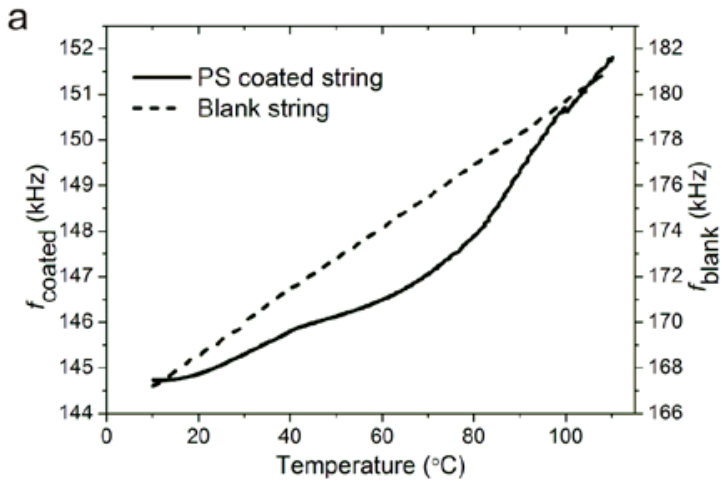

b

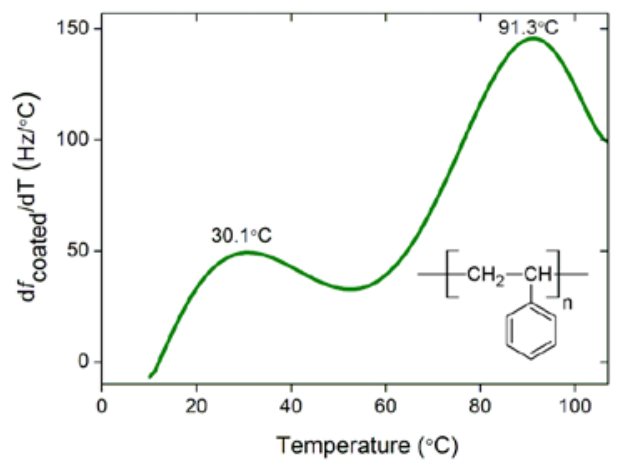

Figure 1 Thermal analysis of PS coated on a $759 \mu \mathrm{m}$ long, $14 \mu \mathrm{m}$ wide and $340 \mathrm{~nm}$ thick SiN microstring. (a) Resonance frequency change reflecting static stress change. (b) The derivative plot of the resonance frequency and two peaks 
indicating the $\alpha$ and the $\beta$ relaxation. The chemical structure of PS is shown.

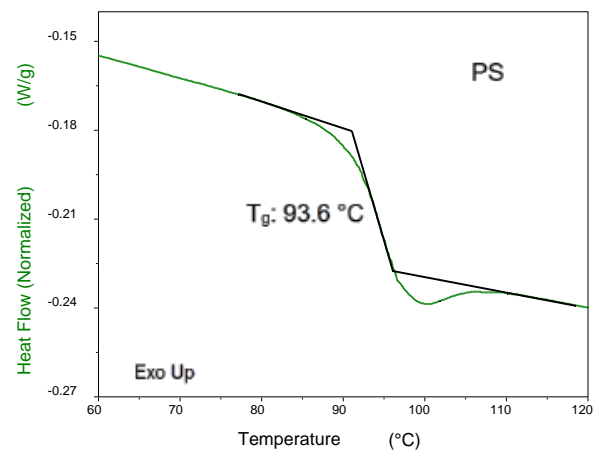

Figure 2 DSC thermogram of PS showing the midpoint of the endothermic shift as $T_{\mathrm{g}}$.

To confirm our finding with PS, we repeated the experiments with PMMA coated microstrings. The change in resonance frequency of a blank and a PMMA coated string and the derivative plot of the resonance frequency are shown in Figure 3 and the DSC plot in Figure 4.
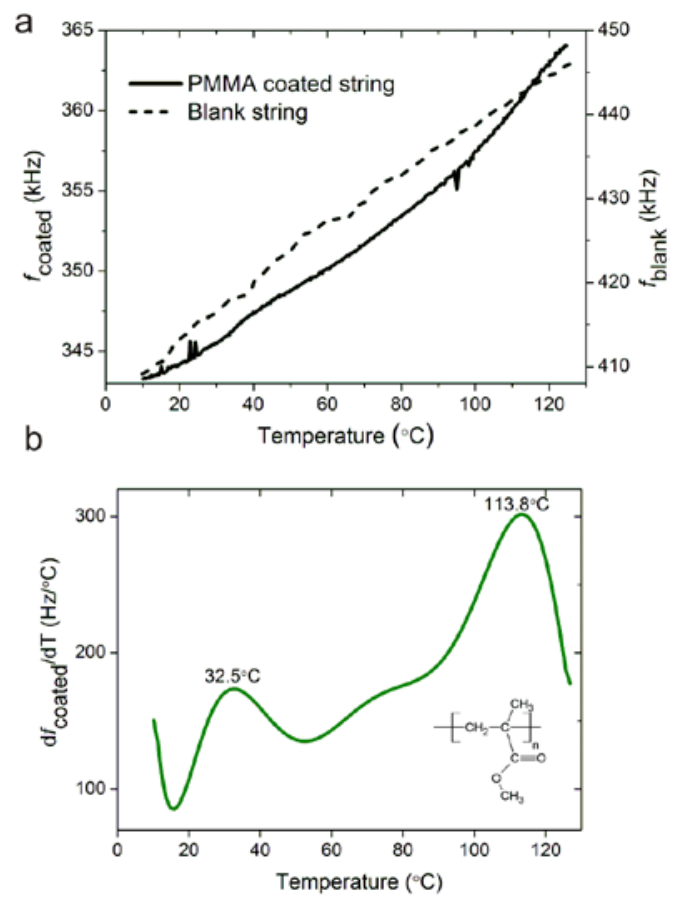

Figure 3 Thermal analysis of PMMA deposited on a $311 \mu \mathrm{m}$ long, $14 \mu \mathrm{m}$ wide and $340 \mathrm{~nm}$ thick SiN microstring. (a) Resonance frequency change reflecting static stress change (b) The derivative plot of the resonance frequency with two peaks indicating the $\alpha$ and the $\beta$ relaxation. The chemical structure of PMMA is shown.

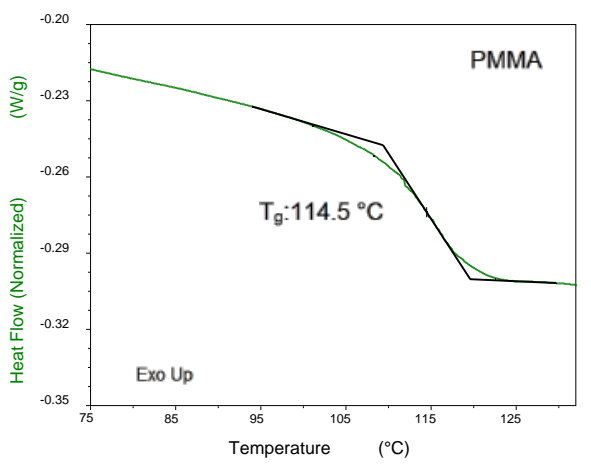

Figure 4. DSC thermogram of PMMA showing the midpoint of the endothermic shift as Tg.

The overall behavior with two peaks seen for the PS is also seen for the PMMA. The $\alpha$ relaxation appears at $113.8^{\circ} \mathrm{C}$ which matches well with the $114.5^{\circ} \mathrm{C}$ obtained from the DSC measurement shown in Figure 4. The local segmental motion coupled with side-group relaxation ${ }^{25}$ in PMMA gives rise to the $\beta$ peak at $32.5^{\circ} \mathrm{C}$ which is very well matching the reported $\mathrm{T}_{\beta}$ at $35^{\circ} \mathrm{C} .^{23}$ These experiments were repeated three times to confirm the reported data. An error of $\pm 2^{\circ} \mathrm{C}$ was estimated ${ }^{16}$ in the extraction of the relaxation temperatures mainly as a result of the uncertainty in the estimation of the actual temperature of the microstrings.

Silicon nitride microstrings were successfully utilized to determine the $\alpha$ and $\beta$ relaxation temperature of PS and PMMA. The advantage of characterizing with MTA lies in its potential to measure both $\alpha$ and $\beta$ relaxations with only few nanograms of sample in quasi-static conditions. The nanogram sample size reaches fast thermal equilibrium and measurements can thus be conducted in less time than conventional techniques with no effect of frequency. Highly sensitive tools like microstrings could also be employed to measure low calorimetric transitions shown by some drugs or proteins along with polymers. E.g. the molecular mobility determines the physical and chemical stability of amorphous pharmaceutical drugs and the knowledge of the 
mechanical relaxations of such samples is crucial to determine their stability.

\section{EXPERIMENTAL}

The used PS ( $\left.M_{w} 20,000 \mathrm{~g} / \mathrm{mol}\right)$ was synthesized by anionic polymerization in cyclohexane at $30^{\circ} \mathrm{C}$ using sec-butyl lithium as initiator. ${ }^{26}$ PMMA $\left(M_{w} 35,000 \mathrm{~g} / \mathrm{mol}\right)$ was purchased from Scientific Polymer Products, Inc., USA and used as received. SiN microstrings used in this study were fabricated by standard microfabrication techniques from low-stress silicon-rich silicon nitride. ${ }^{11} 0.5$ wt\% of PS and PMMA polymer solutions in chloroform (Sigma Aldrich) was prepared. Spray coating ${ }^{27}$ on one side of the strings was done with an Exacta Coat Ultrasonic Spraying System (Sonotek, USA). Coating inhomogeneity has a negligible effect as it only affects the absolute resonance frequency of the microstrings but not the relative temperaturedependent change from which the relaxation temperatures are extracted. ${ }^{16}$ From white light interferometry, a thickness of $\sim 1 \mu \mathrm{m}$ was obtained for PMMA. From the polymer layer thicknesses and the dimensions of the strings used, a rough estimate of the total PS and PMMA mass of $11 \mathrm{ng}$ and $5 \mathrm{ng}$, respectively, was made, assuming a mass density of $1050 \mathrm{~kg} / \mathrm{m}^{3}$ for PS and $1180 \mathrm{~kg} / \mathrm{m}^{3}$ for PMMA. The resonance frequencies of the strings before and after coating as well as during the temperature sweeps were measured with a laser-Doppler vibrometer (MSA-500, Polytec $\mathrm{GmbH}$, Germany). The temperature sweep data was fitted with a polynomial curve and differentiated to identify the maximal local slope changes. The experimental set up is the same as described in the previous publication. ${ }^{16}$ The silicon chip comprising the microstrings was placed on a copper block attached to a Peltier element used for heating and cooling. A resistance temperature detector (PT-1000) was embedded inside the copper block for measuring the temperature which was controlled by a LabVIEW based PID controller. The microstrings were measured in high vacuum at a pressure below $3 \times 10^{-5} \mathrm{mbar}$. The strings were actuated with an external piezoelectric element glued to the copper block. For the PS coated string the temperature was varied from $10^{\circ} \mathrm{C}$ to $110^{\circ} \mathrm{C}$ and from $10^{\circ} \mathrm{C}$ to $120^{\circ} \mathrm{C}$ for the PMMA coated string at a heating rate of $30^{\circ} \mathrm{C} / \mathrm{min}$. Finite element method (FEM) simulations (Comsol 4.2) were conducted to investigate the difference in measured temperature and the actual temperature on the strings due to heat loss to the surroundings through radiation. All the temperatures reported are corrected accordingly. For the FEM simulations, thermal conductivities ${ }^{28,29}$ of $\mathrm{Si}$, SiN, PS, and PMMA were considered to be 130 , $3.2, \quad 0.15$ and $0.2 \mathrm{~W} /(\mathrm{m} \mathrm{K})$, respectively. Emissivities $^{30,31}$ of $0.01,0.95,0.82$ and 0.9 were assumed for $\mathrm{Si}, \mathrm{SiN}, \mathrm{PS}$ and PMMA respectively. The polymer coated strings were subjected to repeated heating-cooling cycles in order to remove the thermal history prior to each measurement. DSC studies of PS and PMMA were performed with a Discovery DSC from TA Instruments with heat-cool-heat cycles from $20{ }^{\circ} \mathrm{C}$ to $150{ }^{\circ} \mathrm{C}$ at a heating and cooling rate of $10{ }^{\circ} \mathrm{C} / \mathrm{min}$. Studies have shown that the variation of $T_{\mathrm{g}}$ with the thickness of the polymer film sets in the thin film regime (thickness in the range of $50-100 \mathrm{~nm}$ for Polystyrene). ${ }^{32,33}$ In our study the polymer film thickness being around $1 \mu \mathrm{m}$, we are measuring in bulk by MTA as is also done by DSC and no effect of shifting in $T_{g}$ due to thinning of films was observed.

\section{ACKNOWLEDGMENTS}

The authors thank Prof. Peter Sommer-Larsen for his valuable insight for the analysis of the results. This research is supported by the Villum Kann Rasmussen Centre of Excellence "NAMEC" under Contract No.65286 and Villum Foundation's Young Investigator Programme (project no. VKR023125). T.L. acknowledges financial support from the Stanford BioX.

\section{REFERENCES}

O. Yano, Y. Wada, J. Polym. Sci. Part A-2

Polym. Phys. 1971, 9, 669-686. 
(2) L. H. Sperling, Introduction to Physical Polymer Science; Fourth.; John Wiley \& Sons, Inc.: New Jersey, USA, 2005.

(3) A. M. Abdul-Fattah, K. M. Dellerman, R. H. Bogner, M. J. Pikal, J. Pharm. Sci. 2007, 96, 1237-1250.

(4) R. Reddy, L. L. Chang, S. Luthra, G. Collins, C. Lopez, S. L. Shamblin, M. J. Pikal, L. A. Gatlin, E. Y. Shalaev, J. Pharm. Sci. 2009, 98, 81-93.

(5) S.P. Duddu, K.J. Weller, Pharm. Sci. 1996, 85, 345-347.

(6) J. Foreman, S. Sauerbrunn, C. Marcozzi, Exploring the sensitivity of thermal analysis techniques to the glass transition Document reference: TA082 http://www.tainst.com (accessed Dec 20, 2014).

(7) K.P. Menard, Dynamic mechanical analysis a practical introduction; Second.; CRC Press: New Jersey, USA, 1999.

(8) W. G. F. Sengers, O. van den Berg, M. Wübbenhorst, A. D. Gotsis, S. J. Picken, Polymer 2005, 46, 6064-6074.

(9) B. Jakobsen, K. Niss, C. Maggi, N. B. Olsen, T. Christensen, J. C. Dyre, J. Non. Cryst. Solids 2011, 357, 267-273.

(10) R. P. Chartoff, J. D. Menczel, S. H. Dillman, Thermal Analysis of Polymer Fundamental and Applications; John Wiley \& Sons, Inc.: New Jersey, USA, 2009.

(11) S. Schmid, S. Dohn, A. Boisen, Sensors 2010, 10, 8092-8100.

(12) H. P. Lang, M. K. Baller, R. Berger, C. Gerber, J.K Gimzewski, F.M. Battiston, P.
Fornaro, J. P. Ramseyer, E. Meyer, H.J Güntherodt, Anal. Chim. Acta 1999, 393, 59-65.

(13) S. Schmid, S. Kühne, C.J. Hierold, Micromech. Microeng. 2009, 19, 065018.

(14) T. Larsen, S. Schmid, L. Grönberg, A.O. Niskanen, J. Hassel, S. Dohn, A. Boisen, Appl. Phys. Lett. 2011, 98, 121901.

(15) T. Larsen, S. Schmid, L. Villanueva, A. Boisen, ACS Nano 2013, 7, 61886193.

(16) S. Bose, S. Schmid, T. Larsen, S. S. Keller, P. Sommer-Larsen, A. Boisen, K. Almdal, ACS Macro Lett. 2014, 3, 55-58.

(17) B. Wunderlich, Thermal analysis of polymeric materials; Springer Berlin Heidelberg: The Nederlands, 2005.

(18) K. Magnus, K. Popp, In Schwingungen; Teubner: Stuttgart, 2005.

(19) Y. Miwa, O. Urakawa, A. Doi, K. Yamamoto, S. Nobukawa, J. Phys. Chem 2012, 116, 1282-1288.

(20) K. Pathmanathan, G.P Johari, J. P. Faivre, L. Monnerie, J. Polym. Sci. Part B Polym. Phys. 1986, 24, 1587-1595.

(21) L. Struik, Polymer 1987, 28, 1869-1875.

(22) C. Robertson, G. Wilkes, Polymer 2000, 41, 9191-9204.

(23) N. McCrum, B. Read, G. Williams, Anelastic and dielectric effects in polymeric solids; Dover Publications: New York, 1991.

(24) C. I. Chung, J. A. Sauer, J. Polym. Sci. Part A-2 Polym. Phys. 1971, 9, 1097-1115. 
(25) S. Gross, D. Camozzo, V. Di Noto, L. Armelao, E. Tondello, Eur. Polym. J. 2007, 43, 673-696.

(26) S. Ndoni, Rev. Sci. Instrum. 1995, 66, $1090-1095$.

(27) S. Bose, S. S Keller, T. S. Alstrøm, A. Boisen, K. Almdal, Langmuir 2013, 29, 6911-6919.

(28) R. Sultan, A.D. Avery, G. Stiehl, B. L. Zink, J. Appl. Phys. 2009, 105, 043501.

(29) S. Yu, P. Hing, X. Hu, Compos. Part A Appl. Sci. Manuf. 2002, 33, 289-292.

(30) N. M. Ravindra, S. Abedrabbo, F. M. Tong, A. K. Nanda, A. C. Speranza, IEEE Trans. Semicond. Manuf. 1998, 11, 3039.

(31) H. A. Babrekar, N. V. Kulkarni, J. P. Jog, V. L. Mathe, S. V. Bhoraskar, Mater. Sci. Eng. B 2010, 168, 40-44.

(32) C.B. Roth, K.L. McNerny, W.F. Jager, J.M. Torkelson, Macromolecules 2007, 40, 2568-2574.

(33) Y. Fujii, H. Morita, A.T.K. Takahara, In Glass Transition, Dynamics and Heterogeneity of Polymer Thin Films; T, Kanaya, Ed.; Springer, 2013; Vol. 252. 


\section{GRAPHICAL ABSTRACT}

Sanjukta Bose ${ }^{1}$, Silvan Schmid ${ }^{1}$, Tom Larsen ${ }^{2}$, Stephan Sylvest Keller ${ }^{1}$, Anja Boisen ${ }^{1}$ and Kristoffer Almdal ${ }^{1}$ Micromechanical fast quasi-static detection of $\alpha$ and $\beta$ relaxations with nanograms of polymer

Microstring resonators have been used as analytical tool for detecting $\alpha$ relaxation and secondary $\beta$ relaxation temperatures of polymers. The advantage of using microstring resonators is their sensitivity to detect very subtle secondary relaxation with only few nanograms of sample, thus overcoming some of the limitations of conventional techniques. Thin films of polymers have been spray coated on the microstrings and the change in resonance frequency has been monitored to detect the relaxation temperatures.
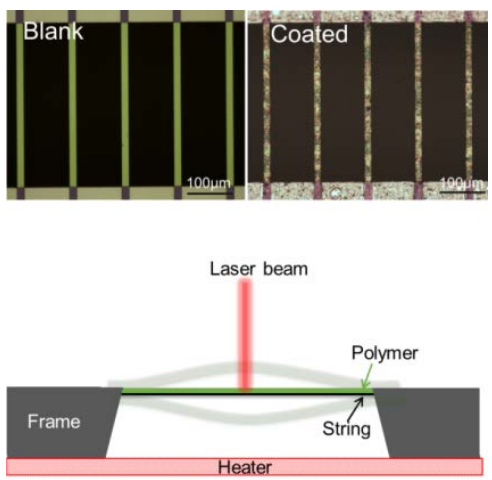